\title{
Development of betulinic acid as an agonist of TGR5 receptor using a new in vitro assay
}

\author{
This article was published in the following Dove Press journal: \\ Drug Design, Development and Therapy \\ 22 August 2016 \\ Number of times this article has been viewed
}

\author{
Shih-Hsiang Lo ${ }^{1,2}$ \\ Kai-Chung Cheng ${ }^{3}$ \\ Ying-Xiao $\mathrm{Li}^{3,4}$ \\ Chin-Hong Chang ${ }^{4,5}$ \\ Juei-Tang Cheng $g^{4,6}$ \\ Kung-Shing Lee L,8 $^{7,8}$ \\ 'Division of Cardiology, Department \\ of Internal Medicine, Zhongxing \\ Branch of Taipei City Hospital, \\ ${ }^{2}$ Department of History and \\ Geography, University of Taipei, \\ Taipei, Taiwan; ${ }^{3}$ Department of \\ Psychosomatic Internal Medicine, \\ Kagoshima University Graduate \\ School of Medical and Dental \\ Sciences, Kagoshima, Japan; \\ ${ }^{4}$ Department of Medical Research, \\ ${ }^{5}$ Department of Neurosurgery, \\ Chi-Mei Medical Center, Yong \\ Kang, ${ }^{6}$ Institute of Medical Science, \\ College of Health Science, Chang \\ Jung Christian University, Tainan, \\ ${ }^{7}$ Department of Surgery, Pingtung \\ Hospital, ${ }^{8}$ Division of Neurosurgery, \\ Department of Surgery, Kaohsiung \\ Medical University Chung-Ho \\ Memorial Hospital, School of \\ Medicine, Kaohsiung Medical \\ University, Kaohsiung, Taiwan
}

Correspondence: Juei-Tang Cheng Institute of Medical Sciences, Chang Jung Christian University, I Changzon Road,

Gueiren, Tainan, 7II0I, Taiwan

$\mathrm{Tel}+886625 \mathrm{I} 7864$

Fax +88662832639

Email jtcheng@mail.cjcu.edu.tw

Kung-Shing Lee

Department of Surgery, Kaohsiung Medical University, I00 Shih-Chuan

First Road, Kaohsiung, 80708, Taiwan

Tel +8867331 8839

Fax +88677365822

Email leekungshing@yahoo.com.tw
Background: G-protein-coupled bile acid receptor 1, also known as TGR5 is known to be involved in glucose homeostasis. In animal models, treatment with a TGR5 agonist induces incretin secretion to reduce hyperglycemia. Betulinic acid, a triterpenoid present in the leaves of white birch, has been introduced as a selective TGR 5 agonist. However, direct activation of TGR 5 by betulinic acid has not yet been reported.

Methods: Transfection of TGR5 into cultured Chinese hamster ovary (CHO-K1) cells was performed to establish the presence of TGR5. Additionally, TGR5-specific small interfering RNA was employed to silence TGR5 in cells (NCI-H716 cells) that secreted incretins. Uptake of glucose by CHO-K1 cells was evaluated using a fluorescent indicator. Amounts of cyclic adenosine monophosphate and glucagon-like peptide were quantified using enzyme-linked immunosorbent assay kits.

Results: Betulinic acid dose-dependently increases glucose uptake by CHO-K1 cells transfected with TGR5 only, which can be considered an alternative method instead of radioligand binding assay. Additionally, signals coupled to TGR5 activation are also increased by betulinic acid in cells transfected with TGR5. In NCI-H716 cells, which endogenously express TGR5, betulinic acid induces glucagon-like peptide secretion via increasing calcium levels. However, the actions of betulinic acid were markedly reduced in NCI-H716 cells that received TGR5-silencing treatment. Therefore, the present study demonstrates the activation of TGR5 by betulinic acid for the first time.

Conclusion: Similar to the positive control lithocholic acid, which is the established agonist of TGR5, betulinic acid has been characterized as a useful agonist of TGR5 and can be used to activate TGR5 in the future.

Keywords: $\mathrm{CHO}-\mathrm{K} 1$ cell, lithocholic acid, NCI-H716 cell, transfection, siRNA

\section{Introduction}

It has been established that G-protein-coupled bile acid (BA) receptor 1 (also known as TGR5) agonists show potential for treating diabetic disorders. ${ }^{1,2}$ Essentially, BA induces TGR5 receptor internalization, activation of extracellular signal-regulated kinase, and intracellular cyclic adenosine monophosphate (cAMP) production in cells. ${ }^{1,2}$ In animal models, treatment with TGR5 agonist(s) produces glucagon-like peptide (GLP-1) secretion, which in turn induces insulin secretion to lower blood glucose and/or increase the basal energy expenditure. ${ }^{3}$ Therefore, TGR5 has been recognized as a target for developing new antidiabetic agents. ${ }^{4}$ In the gut, BAs are also modified by the gut flora to produce secondary BAs, deoxycholic acid, and lithocholic acid (LCA). BAs can be divided into hydrophobic and hydrophilic subgroups. LCA is hydrophobic and could activate TGR5 $5^{5}$ but was highly toxic to liver. ${ }^{6}$ 


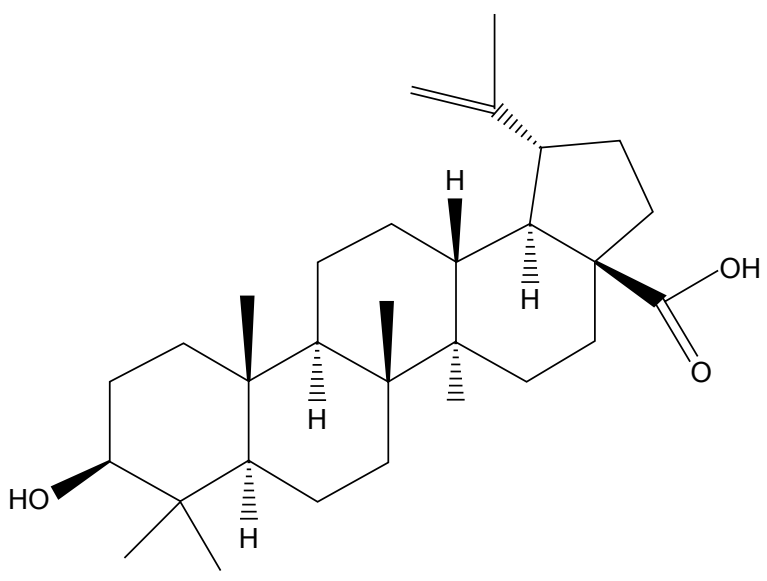

Figure I Chemical structure of betulinic acid.

Betulinic acid, a triterpenoid, as shown in Figure 1, that is present in the leaves of white birch, has been introduced as a selective TGR5 agonist with moderate potency to produce antihyperglycemic actions. ${ }^{7,8}$ Due to its potential as a TGR5 agonist, derivatives of betulinic acid have widely been studied. ${ }^{9,10}$ Recently, the antidiabetic action of betulinic acid has been reviewed with two other triterpenic acids, oleanolic acid, and ursolic acid, in detail. ${ }^{11}$ However, the activation of TGR5 was not shown in that report, probably due to poor evidence. Therefore, data showing the direct effect of betulinic acid on TGR5 are likely to be helpful.

In the present study, we used cells transfected with TGR5 to identify the effect of betulinic acid. Additionally, TGR5silenced cells were applied to confirm the deletion of betulinic acid-induced actions. Therefore, the TGR5-mediated actions of betulinic acid can be observed directly.

\section{Materials and methods \\ Materials}

Betulinic acid (Tokyo Chemical Institute, Tokyo, Japan) and LCA (Sigma-Aldrich Chemical Co., St Louis, MO, USA) were dissolved in dimethyl sulfoxide. Additionally, myristoylated PKI 14-22 amide (Tocris, Avonmouth, Bristol, UK), an inhibitor of protein kinase A, was dissolved in an aqueous solution. Protein was assayed using a bicinchoninic acid assay kit (Thermo Sci., Rockford, IL, USA).

\section{Cell cultures}

The commercial human NCI-H716 cells (BCRC No CCL251) obtained from the Culture Collection and Research Center of the Food Industry Institute (Hsin-Chiu, Taiwan) were maintained in medium supplemented with $10 \%(\mathrm{v} / \mathrm{v})$ fetal bovine serum and $2 \mathrm{mM}$ L-glutamine at $5 \% \mathrm{CO}_{2}$.
Additionally, Chinese hamster ovary (CHO-K1) cells (BCRC No CCL-61) were maintained in growth medium composed of F-12K supplemented with $10 \%$ fetal bovine serum. Cells were subcultured once every 3 days by trypsinization (GIBCO-BRL Life Technologies, Gaithersburg, MD, USA), and the medium was changed every $2-3$ days.

\section{Transfection of TGR5 in CHO-KI cells}

As described in a previous report, ${ }^{12} \mathrm{CHO}-\mathrm{K} 1$ cells were transiently transfected with human G-protein-coupled BA receptor 1 and an expression vector (pCMV6-Entry; OriGene, Rockville, MD, USA). We used the TurboFect transfection reagent (Thermo Fisher Scientific, Pittsburgh, PA, USA) to transfect the cells, which were seeded at $5 \times 10^{4}$ cells per well in six-well plates. Twenty-four hours later, the success of transfection was confirmed using the Western blotting analysis. Then, the TGR5-CHO-K1 cells were incubated with betulinic acid or LCA at the indicated concentrations.

\section{Uptake of 2-NBDG into CHO-KI cells}

Similar to our previous report, ${ }^{13}$ glucose uptake into cells was investigated using 2-(N-[7-nitrobenz-2-oxa-1,3-diazol-4-yl] amino)-2-deoxyglucose (2-NBDG) as a fluorescent indicator. Each assay used $1 \times 10^{6}$ cells $/ \mathrm{mL}$. The medium was removed, and the cells were washed gently with phosphate-buffered solution (PBS). Cells were detached from the dish by trypsinization, suspended in $0.2 \mathrm{mM} 2-\mathrm{NBDG}$ and the testing agent at the indicated concentration in PBS, and then incubated in a $37^{\circ} \mathrm{C}$ water bath for 60 minutes in the dark. The cells were centrifuged $\left(4^{\circ} \mathrm{C}, 5,000 \times g, 10\right.$ minutes $)$, and the supernatant was discarded. The pellet was washed three times with cold PBS and cooled on ice. The pellet was suspended in $1 \mathrm{~mL}$ of PBS. The fluorescence intensity in cell suspension was evaluated using a fluorescence spectrofluorometer (Hitachi F-2000, Tokyo, Japan), with excitation and emission wavelengths of 488 and $520 \mathrm{~nm}$, respectively. The intensity of fluorescence showed the uptake of 2-NBDG in the cells that were incubated with betulinic acid or LCA at the indicated concentrations for suitable time.

\section{Small interfering RNA in NCl-H7l 6 cells}

Based on a previous method, ${ }^{12}$ we purchased a validated small interference RNA (siRNA) targeted against TGR5 from a commercial source (Dharmacon RNA Technology, Lafayette, CO, USA). The validated siRNAs were as follows: ONTARGETplus SMARTpool siTAS1R3 (human NM_152228 sequence), ON-TARGETplus SMARTpool siGNAT3 (human NM_001102386 sequence), and ON-TARGETplus 
SMARTpool siGPBAR1 (TGR5) (human NM_170699 sequence). ON-TARGETplus SMARTpool non-targeting siRNA pool was used as a negative control to distinguish sequence-specific silencing from nonspecific effects. TurboFect transfection reagent (Thermo Fisher Scientific) was used to transfer siRNA. Success of silencing was evaluated using the Western blotting analysis after the transfection. The NCI-H716 cells were transfected with siRNA and differentiated for another 24 hours before the assay.

\section{Western blotting analysis}

Cells were harvested 24 hours after transfection and were lysed with ice-cold lysis buffer containing $300 \mathrm{mmol} / \mathrm{L}$ $\mathrm{NaCl}, 20 \mathrm{mmol} / \mathrm{L}$ Tris- $\mathrm{HCl}$ (pH 7.8), 2 mmol/L ethylenediaminetetraacetic acid, $2 \mathrm{mmol} / \mathrm{L}$ dithiothreitol, 2\% Nonidet P-40, $0.2 \%$ sodium lauryl sulfate, and a cocktail of protease inhibitors (Sigma-Aldrich). Then, $30 \mu \mathrm{g}$ of cell lysate was separated by $10 \%$ sodium dodecyl sulfate-polyacryl-amide gel electrophoresis. The blots were then transferred to polyvinylidene difluoride membranes (Millipore, Billerica, MA, USA). After blocking with $10 \%$ skim milk for 1 hour, the blots were developed using a primary antibody against TGR5 (Abcam, Rockville, MD, USA). The blots were subsequently hybridized using horseradish peroxidase-conjugated goat antirabbit or antimouse immunoglobulin $\mathrm{G}$ (Calbiochem, San Diego, CA, USA) and developed using a chemiluminescence kit (PerkinElmer, Waltham, MA, USA). The optical densities of the bands for TGR5 (32 kDa) and $\beta$-actin (43 kDa) were determined using GEL-PRO ANALYSER software 4.0 (Media Cybernetics, Silver Spring, MD, USA), and quantified as the ratio to $\beta$-actin.

\section{Measurement of intracellular calcium}

Changes in intracellular calcium concentrations were detected using the fluorescent probe fura-2. In brief, NCIH716 cells were placed in a buffered physiological saline solution (PSS), to which $5 \mathrm{mmol} / \mathrm{L}$ fura-2 was added. Cells were then incubated for 1 hour in humidified $5 \% \mathrm{CO}_{2}$ and $95 \%$ air at $37^{\circ} \mathrm{C}$. Then, cells were washed and incubated for an additional 30 minutes in PSS. The cells were inserted into a preheated $\left(37^{\circ} \mathrm{C}\right)$ cuvette containing $2 \mathrm{~mL}$ PSS, and the testing agent at the indicated concentration for the mentioned time. In addition, in some experiments, TGR5-deleted NCI-H716 cells were incubated with the testing agent in the same manner. Fluorescence was recorded continuously using a fluorescence spectrofluorometer (F-2000; Hitachi, Tokyo, Japan). Values of $\left[\mathrm{Ca}^{2+}\right]$ i were determined, as described in our previous report. ${ }^{14}$ Background autofluorescence was measured in unloaded cells and was subtracted from all measurements.

\section{GLP-I secretion from $\mathrm{NCl}-\mathrm{H} 7 \mathrm{I} 6$ cells}

After being cultured for 48 hours, NCI-H716 cells $\left(5 \times 10^{5}\right.$ cells per well) were placed in buffered PSS containing betulinic acid or positive control (LCA) at the indicated concentration to incubate under $37^{\circ} \mathrm{C}$ for 1 hour. The supernatants were collected and immediately assayed using a GLP-1 active enzyme-linked immunosorbent assay kit (EZGLP1T-36K, EMD Millipore Co., Billerica, MA, USA). Experiments were performed in duplicate from the indicated samples.

\section{Measurement of intracellular cAMP levels}

The TGR5-CHO-K1 cells were plated at $5 \times 10^{4}$ cells/well in 96-well plates and incubated with betulinic acid or LCA at the indicated concentrations for 72 hours before cAMP measurements. Intracellular cAMP accumulation was measured using a cAMP enzyme-linked immunosorbent assay kit (ADI-900-066, Enzo Life Sciences, Farmingdale, NY, USA). Experiments were performed in duplicate from the indicated samples.

\section{Statistical analysis}

Results are presented as the mean \pm standard error of the mean from the sample number(n) of each group. One-way analysis of variance was followed by post hoc Tukey's test and $t$-test using SPSS for Windows, version 17 (SPSS Inc., Chicago, IL, USA). Two-tailed $P \leq 0.05$ was considered significant.

\section{Results}

\section{Betulinic acid increases glucose uptake in TGR5-transfected $\mathrm{CHO}$ cells}

The successful transfection of TGR receptor into CHO-K1 cells was confirmed using Western blots, as shown in Figure 2A. Then, we investigated the functional response of TGR5-transfected CHO-K1 cells using glucose uptake as an indicator. Similar to the action of LCA, betulinic acid increases glucose uptake in a dose-dependent manner. However, glucose uptake was not induced by betulinic acid (Figure 2B) or LCA (Figure 2C) in CHO-K1 cells transfected with empty vector. We also evaluated the possibility of cytotoxicity induced by betulinic acid in CHO-K1 cells transfected with TGR5 receptor or with empty vector. Betulinic acid at the highest dose $(0.1 \mathrm{mM})$ did not influence the viability of TGR5-transfected $\mathrm{CHO}-\mathrm{K} 1$ cells or $\mathrm{CHO}-\mathrm{K} 1$ cells transfected with empty vector only in the preliminary experiments. Similar results of the MTT assay were observed 


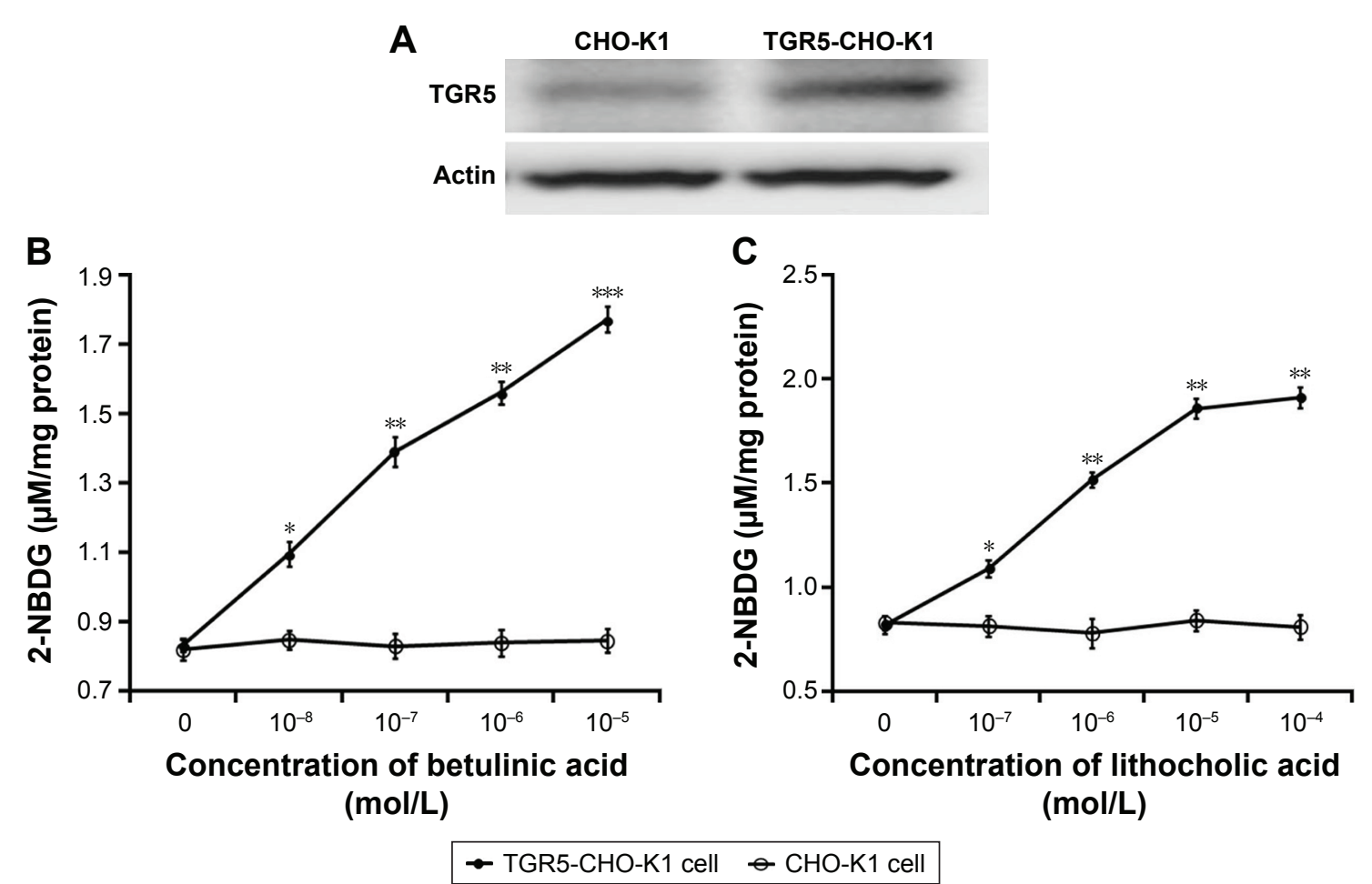

Figure 2 Role of TGR5 in glucose uptake in Chinese hamster ovary (CHO-KI) cells.

Notes: Successful transfection of CHO-KI cells with TGR5 is shown in A. Dose-dependent changes in glucose uptake by betulinic acid in TGR5-transfected CHO-KI cells (TGR5-CHO-KI cells) compared to cells transfected with empty vector (CHO-KI cells) are shown in $\mathbf{B}$. Effects induced by lithocholic acid are shown in $\mathbf{C}$. The uptake of glucose was measured using a commercial kit. Values (mean $\pm \mathrm{SE}$ ) were obtained from eight determinations in each group. $* P<0.05, * * P<0.0 \mathrm{I}$, and $* * * P<0.00 \mathrm{I}$ compared to the vehicle-treated group $(0 \mathrm{~mol} / \mathrm{L})$.

Abbreviations: CHO-KI, Chinese hamster ovary cells; 2-NBDG, 2-[N-(7-nitrobenz-2-oxa-I,3-diazol-4-yl]amino)-2-deoxyglucose; SE, standard error.

in LCA-treated TGR5-transfected CHO-K1 cells or CHO-K1 cells transfected with empty vector only (data not shown).

\section{Betulinic acid increases signals in TGR5-transfected CHO-KI cells}

It has been established that cAMP is the main signal coupled to TGR5 receptor activation. ${ }^{15}$ Therefore, we determined the change of cAMP levels in CHO-K1 cells-expressed TGR5. Betulinic acid induced a marked increase in cAMP levels in cells transfected with TGR5 receptor, but not in cells transfected with empty vector (Figure 3A). The 50\% effective dose value of betulinic acid was $\sim 0.5 \mu \mathrm{M}$. The effect of betulinic acid was produced in a dose-dependent fashion over the same range as that used to increase the glucose uptake. Similarly, LCA (the well-known agonist of TGR5) induced a dose-dependent increase in cAMP levels in CHO-K1 cells transfected with TGR5 receptor (Figure 3B). LCA is known to increase intracellular cAMP levels, ${ }^{3}$ and it was used as a positive control in this study.

Additionally, glucose uptake increased by betulinic acid was markedly reduced by blockade of protein kinase A using protein kinase A inhibitor (PKI) in a dose-related manner
(Figure 4A). Similar results were observed in LCA-treated TGR5-transfected CHO-K1 cells as shown in Figure 4B.

\section{Betulinic acid increases GLP-I secretion in $\mathrm{NCl}-\mathrm{H} 7 \mathrm{I} 6$ cells}

Glucose from the digestion of carbohydrates in foods is the well-known stimulator of GLP-1 secretion in the intestine. ${ }^{16} \mathrm{NCI}-\mathrm{H} 716$ cells are widely used in the study of GLP-1 secretion, ${ }^{17}$ and the presence of TGR5 receptor in NCI-H716 cells has been characterized..$^{10}$ Therefore, we used NCI-H716 cells to investigate the effect of betulinic acid on GLP-1 secretion in vitro. Additionally, as shown in Figure 5A, we applied siRNA to silence TGR5 receptor in NCI-H716 cells.

Betulinic acid increases GLP-1 secretion in a dosedependent manner after incubation with NCI-H716 cells (Figure 5B). Similar changes were also observed in LCAtreated NCI-H716 cells (Figure 5C).

The effectiveness of betulinic acid was markedly attenuated once TGR5 receptor was silenced by siRNA (Figure 5B). Secretion of GLP-1 by betulinic acid was reduced with the absence of TGR5 receptor in NCI-H716 cells. Similar results 

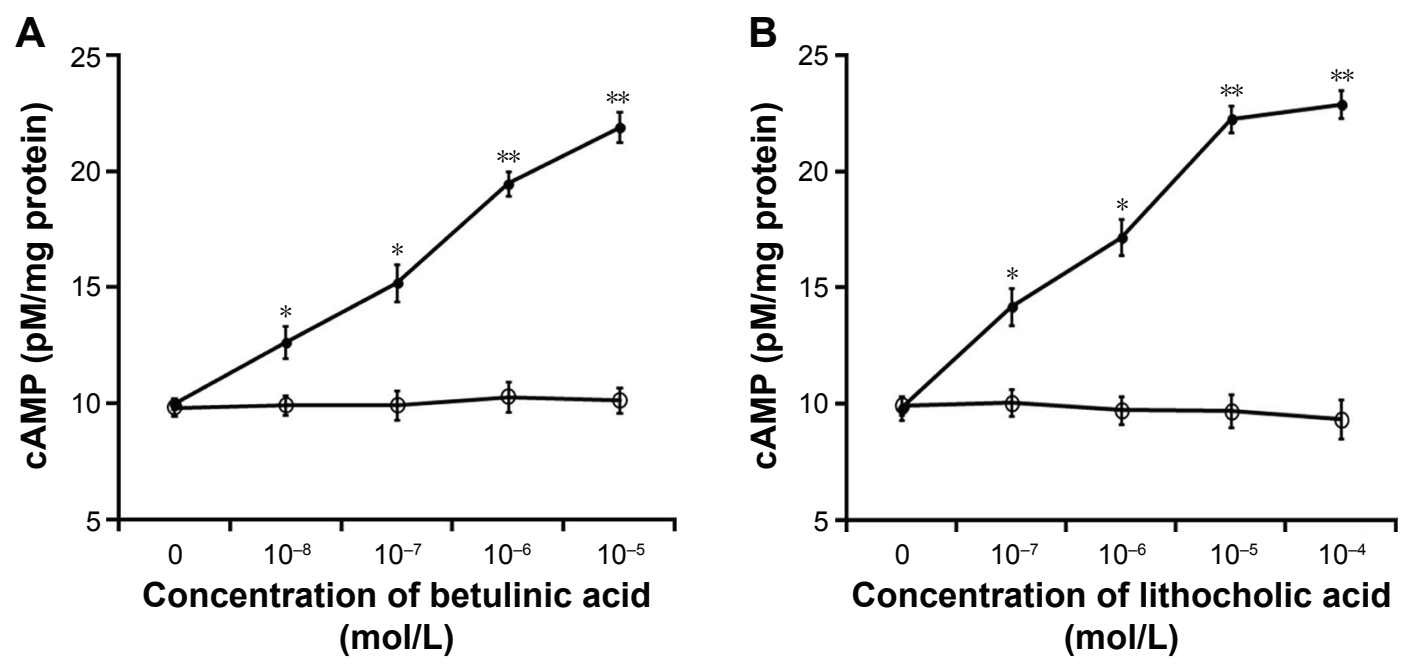

$\rightarrow$ TGR5-CHO-K1 cell $\bullet$ CHO-K1 cell

Figure 3 Changes in cAMP levels in CHO-KI cells.

Notes: Dose-dependent increases in cAMP induced by betulinic acid in TGR5-transfected CHO-KI cells (TGR5-CHO-KI cells) compared with cells transfected with empty vector (CHO-KI cells) are shown in A. Effects induced by lithocholic acid are shown in B. The amount of cAMP was measured using a commercial kit. Values (mean \pm SE) were obtained from eight determinations in each group. $* P<0.05$ and $* * P<0.01$ compared with the vehicle-treated group $(0 \mathrm{~mol} / L)$.

Abbreviations: cAMP, cyclic adenosine monophosphate; $\mathrm{CHO}-\mathrm{KI}$, Chinese hamster ovary cells; SE, standard error.

were also observed in LCA-treated NCI-H716 cells (Figure 5C). This shows that TGR5 receptor mediates the secretion of GLP-1.

\section{Betulinic acid increases calcium levels in $\mathrm{NCl}-\mathrm{H} 7 \mathrm{I} 6$ cells}

We used a nonradioactive assay to determine intracellular calcium levels in NCI-H716 cells because GLP-1 secretion from cells is associated with calcium levels. ${ }^{18}$

Betulinic acid also dose-dependently increases calcium levels in NCI-H716 cells (Figure 6A). Additionally, the same changes were obtained in LCA-treated NCI-H716 cells.
However, the effect of betulinic acid was markedly reduced after TGR5 receptor was silenced by siRNA (Figure 6A). Calcium level increased by betulinic acid was attenuated after the silencing of TGR5 receptor in NCI-H716 cells. Similar results were also produced in LCA-treated NCI-H716 cells (Figure 6B).

\section{Discussion}

In this study, we demonstrated that the natural product betulinic acid is an agonist of TGR5 receptor. Using CHO-K1 cells transfected with human TGR5 receptor, we found for the first time that betulinic acid increases glucose uptake
A

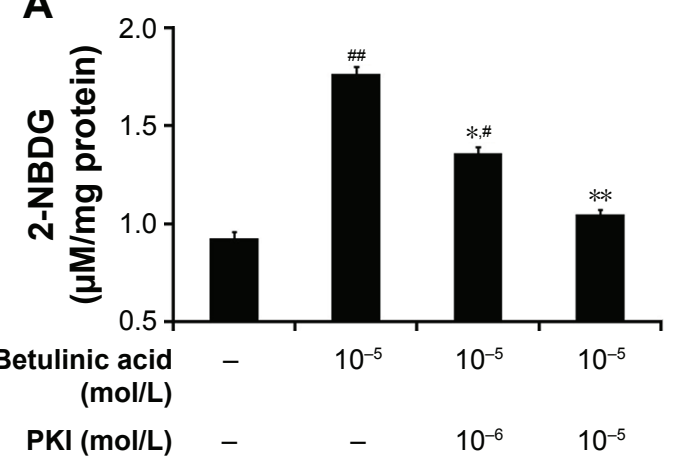

B

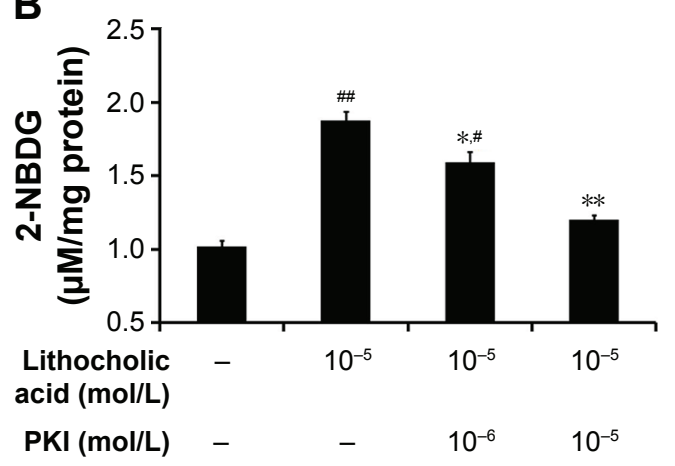

Figure 4 Effect of protein kinase $\mathrm{A}$ inhibition on the changes in glucose uptake in CHO-KI cells.

Notes: Betulinic acid-induced changes in glucose uptake in TGR5-CHO-KI cells were reduced by protein kinase A inhibitor (PKI), as shown in A. Effects induced by lithocholic acid are shown in B. Values (mean $\pm \mathrm{SE}$ ) were obtained from eight determinations in each group. $* P<0.05$ and $* * P<0.01$ compared with the vehicle-treated group. ${ }^{\#} P<0.05$ and ${ }^{\# P}<0.01$ compared with the basal group without treatment.

Abbreviations: CHO-KI, Chinese hamster ovary cells; 2-NBDG, 2-(N-[7-nitrobenz-2-oxa-I,3-diazol-4-yl]amino)-2-deoxyglucose; SE, standard error. 


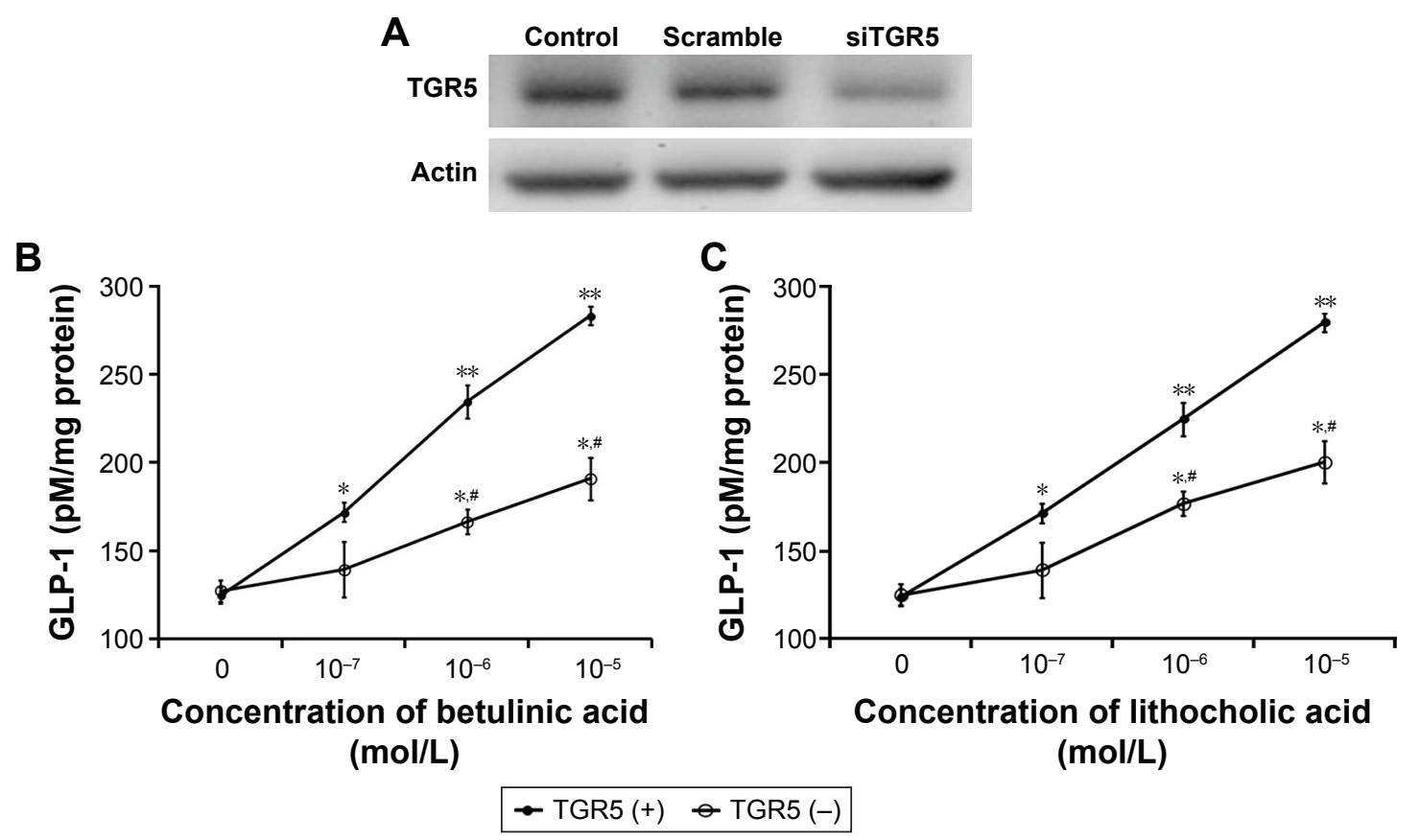

Figure 5 Role of TGR5 in GLP-I secretion from $\mathrm{NCl}-\mathrm{H} 7 \mathrm{I} 6$ cells.

Notes: Success of TGR5 silencing identified in NCl-H7I6 cells is shown in $\mathbf{A}$ where siTGR5 indicates the treatment with TGR5-specific siRNA and scramble indicates the negative control. Dose-dependent increases in GLP-I secretion by betulinic acid in scramble-transfected NCI-H7I6 cells, marked as TGR5 (+) cells, compared with cells that received siRNA targeting TGR5, marked as TGR5 (-) cells, are shown in B. Effects induced by lithocholic acid are shown in C. The amount of GLP-I was measured using a commercial kit. Values (mean $\pm \mathrm{SE}$ ) were obtained from eight determinations in each group. $* \mathrm{P}<0.05$ and $* * P<0.0 \mathrm{I}$ compared with the vehicle-treated group $(0$ mol/L). ${ }^{\#} P<0.05$ compared with that in TGR5 $(+)$ cells at the same concentration.

Abbreviations: GLP-I, glucagon-like peptide-I; SE, standard error; siRNA, small interfering RNA.

through activation of TGR5 receptor. A similar result was also produced using LCA, a well-known agonist of TGR5 receptor and the positive control in this study.

In CHO-K1 cells transfected with TGR5 receptor, betulinic acid increases glucose uptake in a dose-dependent manner.

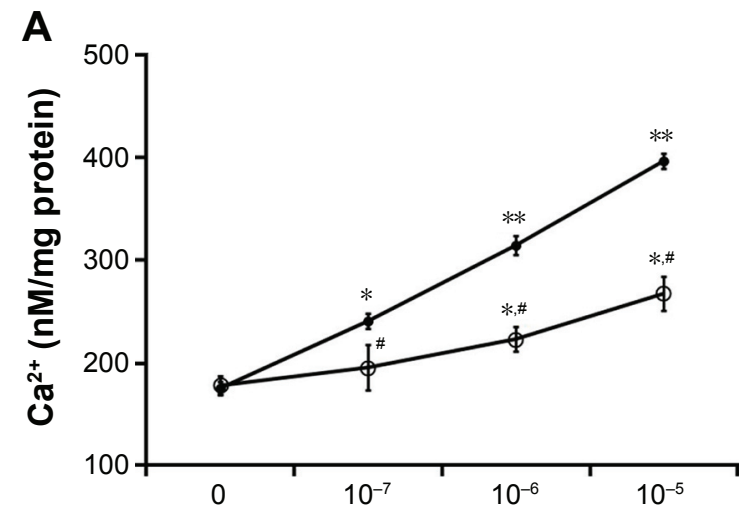

Concentration of betulinic acid $(\mathrm{mol} / \mathrm{L})$
However, similar changes were not observed in CHO-K1 cells transfected with empty vector only. That the same results were observed in LCA-treated cells provide additional support for the betulinic acid-induced glucose uptake through TGR5 receptor. Moreover, betulinic acid dose-dependently

B

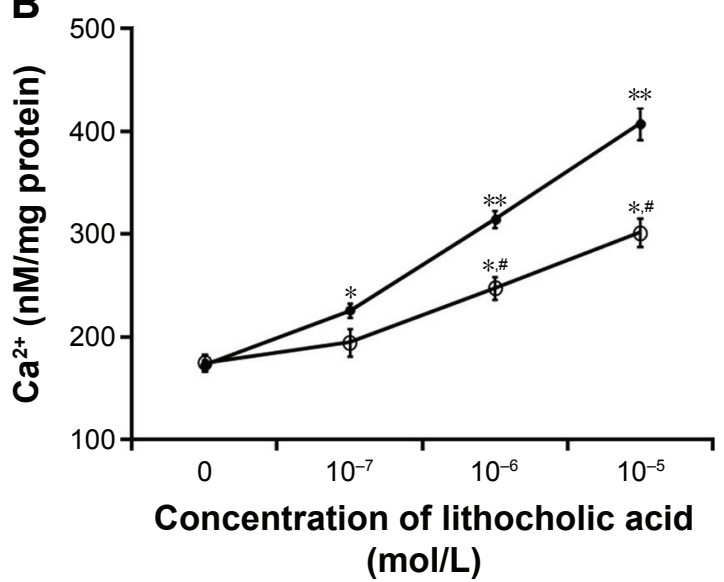

Figure 6 Role of TGR5 in calcium influx into $\mathrm{NCl}-\mathrm{H} 7 \mathrm{I} 6$ cells.

Notes: Dose-dependent increases in cellular calcium $\left(\mathrm{Ca}^{2+}\right)$ induced by betulinic acid in scramble-transfected $\mathrm{NCl}-\mathrm{H} 7 \mathrm{I} 6$ cells, marked as TGR5 $(+)$ cells, compared with cells that received siRNA targeting TGR5, marked as TGR5 (-) cells, are shown in A. Effects induced by lithocholic acid are shown in B. Calcium concentration was measured using fura- 2 assay. Values (mean $\pm \mathrm{SE}$ ) were obtained from eight determinations in each group. $* P<0.05$ and $* * P<0.01$ compared with the vehicle-treated group ( 0 mol/L). ${ }^{\#} P<0.05$ compared with that in TGR5 $(+)$ cells at the same concentration.

Abbreviations: siRNA, small interfering RNA; SE, standard error. 
increases the cAMP level in CHO-K1 cells transfected with TGR5 receptor. Previous report has identified cAMP as the subcellular signal coupled to TGR5 receptor activation, ${ }^{6}$ further supporting the mediation of TGR5 receptor in betulinic acid-induced action. Finally, we applied an inhibitor of protein kinase $\mathrm{A}$ to block the betulinic acid-induced glucose uptake in CHO-K1 cells transfected with TGR5 receptor. It is thus plausible that TGR5 receptors are activated by betulinic acid to enhance glucose uptake through a cAMPdependent pathway. Notably, this view has not been reported previously.

NCI-H716 cells have been introduced as a useful in vitro tool in the study of GLP-1 secretion from the human intestine,${ }^{17}$ and in which GLP-1 secretion has been reported to be linked to increased levels of intracellular calcium. ${ }^{18}$ We found that betulinic acid dose-dependently increased GLP-1 secretion in parallel with the increase in calcium levels in NCI-H716 cells. Similar changes were induced by LCA, the well-known agonist of TGR5 receptor that was used as a positive control in this study. Interestingly, actions of betulinic acid were markedly reduced once TGR 5 receptor was silenced by siRNA in NCI-H716 cells. To produce the stable silencing, the siRNA used for TGR5 receptor included three targets: TAS1R 3 and $\alpha$-gustducin in addition to TGR5 receptor. ${ }^{12}$ However, it has been demonstrated that neither siRNA targeting TAS1R3 nor siRNA targeting $\alpha$-gustducin in NCI-H716 cells influenced the GLP-1 secretion that was induced by a TGR 5 receptor agonist. ${ }^{12}$ TGR5 receptor is known to be a Gos-coupled receptor. ${ }^{19}$ TGR5 receptor activation stimulates GLP-1 secretion via Gos, which increases the intracellular calcium level in NCI-H716 cells. ${ }^{20}$ Our data are consistent with this view, supporting the idea that the action of betulinic acid in NCI-H716 cells to increase GLP-1 secretion occurs mainly through TGR5 receptor activation. Some reports have indicated that betulinic acid is able to induce TGR5 receptor activation. ${ }^{9,10}$ However, direct stimulation of TGR 5 receptor by betulinic acid using radioligand binding assay or similar approaches has still not been reported. Using an alternative method, the present study demonstrated for the first time that betulinic acid-induced action is mediated by TGR5 receptor activation. However, chemical ligand(s) are known to produce nonspecific action, particularly at other receptor sites such as farnesoid X receptor. It is the limitation of this report, and more studies are required to clarify the specificity of betulinic acid in advance.

GLP-1 plays an essential role in the maintenance of glucose homeostasis by its multiple actions, which include stimulation of glucose-dependent insulin secretion, proinsulin gene expression, and $\beta$-cell proliferative and antiapoptotic pathways. ${ }^{21}$ Moreover, GLP-1 regulates energy homeostasis via its neural actions, which include inhibiting glucagon release, gastric emptying, food intake, and appetite. ${ }^{22,23}$ Betulinic acid appears to regulate energy homeostasis via GLP-1 secretion. In addition, betulinic acid has been characterized as an agonist of human TGR5 receptor, which is expressed in the intestine, brown adipose tissue, skeletal muscle, and selected regions of the central nervous system. TGR5 receptor activation is known to regulate glucose and/or energy homeostasis, immune function, and liver function. ${ }^{24}$ Therefore, betulinic acid can produce multiple actions in vivo.

\section{Conclusion}

In the present study, we demonstrated that betulinic acid is an agonist of human TGR5 receptor. Betulinic acid increases glucose uptake and stimulates GLP-1 secretion in cells via TGR5 receptor activation. Therefore, betulinic acid is a potential agent for activating TGR5 receptor, which has multiple actions in vivo.

\section{Acknowledgments}

The authors thank Ya-Pin Lin and Yi-Zhi Chen for their assistance in experiments. We also thank American Journal Expert for editing. This study was supported in part by a grant from the Ministry of Science and Technology (MOST 104-2320B-384-004-MY3) in Taiwan, the Republic of China.

\section{Disclosure}

The authors report no conflicts of interest in this work.

\section{References}

1. Maruyama T, Miyamoto Y, Nakamura T, et al. Identification of membrane-type receptor for bile acids (M-BAR). Biochem Biophys Res Coтmun. 2002;298(5):714-719.

2. Kawamata Y, Fujii R, Hosoya M, et al. A G protein-coupled receptor responsive to bile acids. $J$ Biol Chem. 2003;278(11):9435-9440.

3. Thomas C, Gioiello A, Noriega L, et al. TGR5-mediated bile acid sensing controls glucose homeostasis. Cell Metab. 2009;10(3):167-177.

4. Copple BL, Li T. Pharmacology of bile acid receptors: evolution of bile acids from simple detergents to complex signaling molecules. Pharmacol Res. 2016;104:9-21.

5. De Aguiar Vallim TQ, Tarling EJ, Edwards PA. Pleiotropic roles of bile acids in metabolism. Cell Metab. 2013;17(5):657-669.

6. Fickert P, Fuchsbichler A, Marschall HU, et al. Lithocholic acid feeding induces segmental bile duct obstruction and destructive cholangitis in mice. Am J Pathol. 2006;168(2):410-422.

7. Takikawa HH, Hirooka M, Sasaki M. The first synthesis of ( \pm )-brevione B, an allelopathic agent isolated from Penicillium sp. Tetrahedron Lett. 2003;44(28):5235-5238

8. Blazevski J, Petkovic F, Momcilovic M, et al. Betulinic acid regulates generation of neuroinflammatory mediators responsible for tissue destruction in multiple sclerosis in vitro. Acta Pharmacol Sin. 2013;34(3) 424-431. 
9. Genet C, Strehle A, Schmidt C, et al. Structure-activity relationship study of betulinic acid, a novel and selective TGR5 agonist, and its synthetic derivatives: potential impact in diabetes. J Med Chem. 2010; 53(1):178-190.

10. Wang XY, Zhang SY, Li J, Liu HN, Xie X, Nan FJ. Highly lipophilic 3-epi-betulinic acid derivatives as potent and selective TGR5 agonists with improved cellular efficacy. Acta Pharmacol Sin. 2014; 35(11):1463-1472.

11. Silva FSG, Oliveira PJ, Duarte MF. Oleanolic, ursolic and betulinic acids as food supplements or pharmaceutical agents for type 2 diabetes promise or illusion? J Agric Food Chem. 2016;64(15):2991-3008.

12. Kim K, Park M, Lee YM, Rhyu MR, Kim HY. Ginsenoside metabolite compound K stimulates glucagon-like peptide-1 secretion in NCI-H716 cells via bile acid receptor activation. Arch Pharm Res. 2014;37(9): 1193-1200.

13. Huang CH, Chen MF, Chung HH, Cheng JT. Antihyperglycemic effect of syringaldehyde in streptozotocin-induced diabetic rats. J Nat Prod. 2012;75(8):1465-1468.

14. Cheng KC, Li YX, Asakawa A, et al. Characterization of preptininduced insulin secretion in pancreatic $\beta$-cells. J Endocrinol. 2012; 215(1):43-49.

15. Vettorazzi JF, Ribeiro RA, Borck PC, et al. The bile acid TUDCA increases glucose-induced insulin secretion via the cAMP/PKA pathway in pancreatic beta cells. Metabolism. 2016;65(3):54-63.
16. Steinert RE, Beglinger C. Nutrient sensing in the gut: interactions between chemosensory cells, visceral afferents and the secretion of satiation peptides. Physiol Behav. 2011;105(1):62-70.

17. Kuhre RE, Wewer Albrechtsen NJ, Deacon CF, et al. Peptide production and secretion in GLUTag, NCI-H716, and STC-1 cells: a comparison to native L-cells. J Mol Endocrinol. 2016;56(3):201-211.

18. Le Nevé B, Daniel H. Selected tetrapeptides lead to a GLP-1 release from the human enteroendocrine cell line NCI-H716. Regul Pept. 2011;167(1):14-20.

19. Reimann F, Tolhurst G, Gribble FM. G-protein coupled receptors in intestinal chemosensation. Cell Metab. 2012;15(4):421-431.

20. Behrens M, Meyerhof W. Gustatory and extragustatory functions of mammalian taste receptors. Physiol Behav. 2011;105(1):4-13.

21. Kuhre RE, Holst JJ, Kappe C. The regulation of function, growth and survival of GLP-1-producing L-cells. Clin Sci (Lond). 2016;130(2): 79-91.

22. Drucker DJ. The biology of incretin hormones. Cell Metab. 2006;3(3): 153-165.

23. Lim GE, Brubaker PL. Glucagon-like peptide 1 secretion by the L-cell: the view from within. Diabetes. 2006;55(Suppl 2):S70-S77.

24. Pols TW, Noriega LG, Nomura M, Auwerx J, Schoonjans K. The bile acid membrane receptor TGR5 as an emerging target in metabolism and inflammation. J Hepatol. 2011;54(6):1263-1272.
Drug Design, Development and Therapy

\section{Publish your work in this journal}

Drug Design, Development and Therapy is an international, peerreviewed open-access journal that spans the spectrum of drug design and development through to clinical applications. Clinical outcomes, patient safety, and programs for the development and effective, safe, and sustained use of medicines are the features of the journal, which

\section{Dovepress}

has also been accepted for indexing on PubMed Central. The manuscript management system is completely online and includes a very quick and fair peer-review system, which is all easy to use. Visit http://www.dovepress.com/testimonials.php to read real quotes from published authors. 